\title{
Nephrology Continuous Medical Education in Egypt and Middle East: In Memorial of Professor Hussein Sheashaa.
}

\begin{abstract}
Nephrology education has an important role in medical education. It include a variety of sectors to be fulfilled including the onsite and virtual medical school classroom, clinical nephrology consultation inpatient round, clinical outpatient service and research prospective. The learners in nephrology field vary from students, residents, fellows and nurses staff. Therefore, it is a complex task to provide a continuous medical education in nephrology at a high standard. In this article we discuss the importance of having a Nephrology medical continuous education (NCME) and present a unique experience in the Middle east and Egypt of a pioneer young Nephrology professor Hussein Sheashaa who was the steering force of the NCME of the Egyptian society of Nephrology and transplantation. Work of Professor Hussein is considered a role model to promote new insights in faculty development and encourage NCME a at higher standard level.
\end{abstract}

Keywords: CME nephrology, virtual education, blended workshops, online education courses
Volume 8 Issue 6 - 2020

\author{
Ahmed $\mathrm{AKL}^{1,2,3}$ \\ 'Urology and nephrology center, Mansoura University, Egypt \\ ${ }^{2}$ Dr. Soliman fakeeh hospital, Jeddah, Saudi Arabia \\ ${ }^{3}$ Fakeeh College of Medical sciences, Jeddah, Saudi Arabia
}

\begin{abstract}
Correspondence: Ahmed AKL, MD, FACP, FASN, Consultant of Nephrology \& Transplantation, DSFH, SA

Urology and Nephrology Center, Mansoura University, Egypt,
\end{abstract} Associate Professor, FCMS, SA, Email aiakl200I@yahoo.com

Received: November 04, 2020 | Published: November 18, 2020

\section{Introduction}

Many nephrologists inspire, instruct, and supervise physicians in training through the education spectrum. From structured lectures in classrooms to the daily nephrology consultation service, nephrologists recognized as excellent teachers and mentors to medical students, residents, and fellows in training. ${ }^{1}$ Structured approach and assessment of teaching out goals plans to advance the nephrology patient care is not optimal. ${ }^{2}$ Inspiration by role models to develop an academic and clinical successful career in Nephrology is very important as one person can make the difference and steer on the academic activities with new ideas and competitive performance energizing everyone to gain the best of his work.

\section{A role model of a well developed pioneer nephrology academic professor}

Hussein Sheashaa from Ezzbet Abo-Shaeer a small village in north of Egypt, in 1991 he was graduated from Mansoura Faculty of Medicine and achieved the Medical Bachelor, Bachelor of surgery with Excellence and honor. Starting from 1992, he started his Internal medicine and Nephrology residency program in Urology \& Nephrology center, Mansoura University, Egypt. He was graduated and got his master degree in Nephrology at 1996 from Mansoura University. After two years from starting his residency I joined in the program and I was his junior resident. I remember my first days with him in the hemodialysis unit. He was lecturing me everything starting from medical ethics, basic knowledge and daily interaction with my seniors. It is not as easy as it might appear to survive in the medical field and to build a fruitful life without complications. Hussein was like a brother to me, feeding me every day with the up to date nephrology information's about our work and as well about daily work environment status. I was safe under the support of Hussein as I have a brother caring of me and in many situations defending me. Once Hussein got the doctorate degree in 2002 he initiated the first Nephrology continuous medical activity (NCME) in my city Mansoura under the name of Nephrology club. I remember his energetic activity in documenting the event and reviewing all aspects of the activity in detail starting from the presenters, subject titles and social organization, I learned from him how it was hard to be responsible for a scientific meeting and to maintain such scientific activity at regular basis. Later, his NCME became one of the pillars of the Egyptian society of Nephrology CME programs.

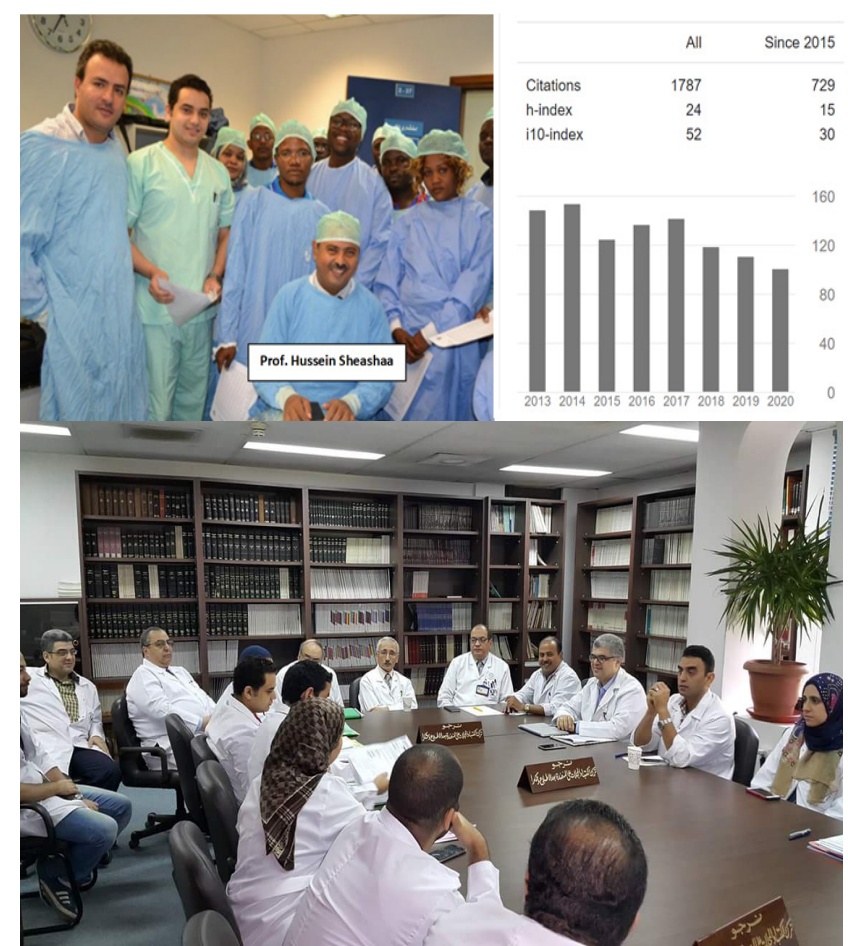

Figure I Prof. Hussein Sheashaa (1968-2020) the pioneer and steering force of CME in Middle east and Egypt among his Nephrology fellows from different African countries receiving their training at the Urology \& Nephrology center, Mansoura University, Egypt. 
He was one of the pioneers to initiate the Egyptian Nephrology fellowship program and among the team initiated the Nephrology doctorate degree in Mansoura University. He was one of the founders of the research center in the College of Medicine, Mansoura University, Egypt with more than 100 well recognized papers in various aspects of nephrology (Figure 1). When I finished my doctorate degree I started my own Nephrology training course supported by the international society of Nephrology. Every training course I was making sure Prof. Hussein to be among the leaders in my meetings not only to acknowledge him but also to keep learning from him. Lastly in the ERA of COVID-19 pandemics and with the lock down of all activities, Prof. Hussein surprised all the nephrology community in Egypt by starting his virtual scientific meetings that was regularly done three times per week. Starting by National Nephrology leader professors from Egypt under the umbrella of the Egyptian society of Nephrology and Transplantation, then the activity grown to involve the Nephrology leaders from all countries of the Middle East.
At regular basis, you could attend to a professor from Saudi Arabia presenting while a professor from UK moderating the meeting. Lastly the President of the American society of Nephrology was a speaker with the president of the Egyptian society of Nephrology as moderator. It was fantastic and fruitful nephrology scientific gathering ever done at a high standard level and ended with creation of the Academy of kidney diseases on youtube with free access for more than 65 lectures with discussion from a high standard professors. On Saturday $31^{\text {st }}$ of October Prof. Hussein academic career has ended suddenly with aggressive heart attack after moderating his last virtual nephrology seminar about management of coronary heart disease in CKD patients. Nephrologists all the over the world are devastated by his leave and the NCME evolution in Middle east will take time to revive again (Table 1$)$.

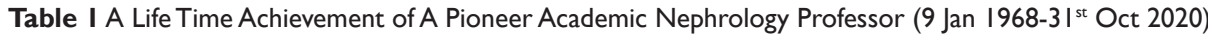

\begin{tabular}{|c|c|}
\hline Academic Activity & Number \\
\hline Publications: & 100 \\
\hline I-Renal Transplantation & 44 \\
\hline 2-Clinical \& Experimental Nephrology \& Dialysis & 51 \\
\hline 3-General Internal Medicine & 5 \\
\hline Nephrology Educational CME: & 85 \\
\hline I. The international Hemodialysis Course Urology and Nephrology & \\
\hline Center, Mansoura University, EGYPT May 2008-2016. & 9 \\
\hline \multicolumn{2}{|l|}{ http://www.ndt-educational.org/El\%20Mansoura20II.htm } \\
\hline \multicolumn{2}{|l|}{ http://www.ndt-educational.org/Mansoura20I2.htm } \\
\hline \multicolumn{2}{|l|}{ http://www.era-edta.org/Mansoura2013.htm } \\
\hline \multicolumn{2}{|l|}{ http://www.ndt-educational.org/page-23-64I-0-673-- } \\
\hline \multicolumn{2}{|l|}{ the7thinternationalhemodialysiscourse.php. } \\
\hline $\begin{array}{l}\text { 2- Egyptian society of Nephrology and Transplantation- Continuous Nephrology Education Courses: ESNT* Center, Cairo } \\
\text { 2012-2016. }\end{array}$ & 5 \\
\hline 3- Egyptian society of Nephrology and Transplantation- Continuous Nephrology Outreach Courses: & 7 \\
\hline
\end{tabular}

4- ESNT-Virtual CME Academy Of Kidney Diseases And Transplantation (Free Access Education):

https://www.youtube.com/user/HusseinSheashaa

$725-1094$

*Egyptian Society Of Nephrology \& Transplantation (ESNT).

\section{Discussion}

Academic nephrologists play different roles as educators Identification and balance of the education roles lead to improvement of the educational interventions that positively affect patient care. The nephrology educational roles vary from supervising learners daily care of patients, direct lecturing in class rooms, teaching the concept of patient-centered care, assessment of the performance of learners and decide what they are ready to do without direct supervision, and distributing constructive feedback. ${ }^{3,4}$ The variety of learners in nephrology field represent a challenge to the nephrology educator to interact with starting with medical students, residents, or fellows. ${ }^{5}$ Comparison of the nephrology teaching roles highlights the opportunity for nephrologist educators to take the lead in developing interprofessional clinical learning experiences. With increasing emphasis on teamwork and collaborative practice noted in training program requirements ${ }^{4}$ these venues could serve as ideal environments for learners from multiple professions to work together and learn about each other's roles and responsibilities.

These interactions could help to improve communication and collaboration among disparate professions, ultimately leading to new ways at looking at old problems. This could be especially beneficial when treating patients with complex health care needs such as CKD. For example, patients nearing the need for RRT involve collaborative practice among physicians, nurses, social workers, nutritionists, pharmacists, nurse practitioners, and physician assistants (ESRD units and transplant settings). The nephrology education roadmap is 
designed to ensure the optimal training of nephrologist to be confident, knowledgeable, need continuous assessment and improvements to reach high standard patient centered care. ${ }^{6}$ Nephrology educators courses should cover mainly 5 topics in educatio ${ }^{1}$ ideologies of education, ${ }^{2}$ teaching tools, ${ }^{3}$ approach to improve educational principles, 4 assessment and validation, and ${ }^{5}$ educational leadership. ${ }^{6} \mathrm{~A}$ formal certified training is mandatory part of nephrologists educators development curriculum that includes master's or doctorate degree in medical education to those planning on devoting a significant portion of their effort to medical education research. ${ }^{7}$

\section{Conclusion}

The Nephrology educator role is to cover all items of educational topics to enhance the work place activities, curriculum design of learners, and patient care activities. The nephrology educators should balance their efforts to transfer the knowledge to achieve a high quality patient-centered care. We presented an example of life time achievement of a nephrology educator who could in short time enrich the scientific community with basic science, clinical research, onsite clinical training courses, virtual nephrology continuous medical education and create a free access online academy of kidney disease in Egypt and Middle East.

\section{Acknowledgements}

I would like to thank the founder of the Urology \&amp; Nephrology center Prof. Mohamed A. Ghoneim, the former chiefs of Nephrology department, Prof. Mohamed Sobh, Prof. Mohamed Adel Bakr, Prof. Ehab Wahba, Prof. Ashraf Foda, Prof. Samir Sally and current chief Prof. Ayman Refaie and all Nephrology staffs of physicians,
Nurses, Engineers, BioMed, and workers for their dedicated work to maintain the place to be at high standard environment for Nephrology Education.

\section{Conflicts of interest}

No conflict of interest.

\section{References}

1. Shah HH, Jhaveri KD, Sparks MA, et al. Career choice selection and satisfaction among US adult nephrology fellows. Clin J Am Soc Nephrol. 2012;7:1513-1520.

2. Jhaveri KD, Wanchoo R, Maursetter L, et al. The need for enhanced training in nephrology medical education research. Am J Kidney Dis. $2015 ; 65: 807-808$.

3. Chen HC, van den Broek WE, ten Cate O. The case for use of entrustable professional activities in undergraduate medical education. Acad Med. 2015;90:431-436.

4. Caverzagie KJ, Cooney TG, Hemmer PA, et al. The development of entrustable professional activities for internal medicine residency training: A report from the Education Redesign Committee of the Alliance for Academic Internal Medicine. Acad Med. 2015;90:479-484.

5. Jhaveri KD, Shah HH, Mattana J. Enhancing interest in nephrology careers during medical residency. Am J Kidney Dis. 2012;60:350-353.

6. Cook DA. Randomized controlled trials and meta-analysis in medical education: what role do they play? Med Teach. 2012;34:468-473.

7. Association of American Medical Colleges: Medical Education Research Certificate (MERC) Program. 2015. 